IRSTI 44.39 .29

\author{
${ }^{1}$ R.K. Manatbayev, N.Kalasov ${ }^{1, *}$, B. Bektibai ${ }^{1}$, Ye.Nurymov ${ }^{1}$, \\ K.Baktybekov², A. Syzdykov², E.M. Zulbukharova ${ }^{1}$ \\ ${ }^{1}$ al-Farabi Kazakh national university, Faculty of physics and technology, \\ Dept. of Thermal physics and Technical Physics, Almaty, Kazakhstan \\ ${ }^{2}$ Kazakhstan Gharysh Sapary, Astana, Kazakhstan \\ *e-mail: kalasov.nurdaulet@gmail.com
}

\title{
Definition of the basic geometric parameters of a carousel type turbine its technological solution
}

\begin{abstract}
In the last 10-15 years, the use of wind energy has been developing rapidly. To date, more than 20,000 wind power units have been installed in the world, the total capacity of which exceeds several MW. Kazakhstan has significant resources of wind energy. The most known in this respect are the resources of the Dzungar Gate and Shelek Complex, located in the Almaty region (Kazakhstan). Their possibilities for use in the generation of electric power of air flows are unique.

In this paper, the main calculations for determining the influence of the design characteristics of the Darrieus wind turbine on its energy efficiency are presented. The dependence of the maximum coefficient of wind energy use of vertical axle wind wheels on the number of blades at a constant filling factor $\sigma$, on the number of blades at their constant width, on the lengthening of the blade $\lambda$ is studied. Based on these results, design characteristics for a rotor with a power of $1 \mathrm{~kW}$ are determined, and a diagram of the wind turbine which can provide thermal protection of the wind turbine by using natural ventilation of warm air inside the rotating elements of the windmill arising from centrifugal forces is also given.

And another way of solving the technological problem is proposed. Renounce a long rotating shaft and replace it with a short axis, on which two bearings will rotate with a wind wheel attached to them. Application of the proposed design of the wind farm will simplify the manufacturing technology.

Key words: wind turbine, Darrieus, aero dynamical characteristics, natural ventilation, geometrical parameters
\end{abstract}

\section{Introduction}

The development of a reliable method of protecting a working wind turbine from adverse weather conditions is relevant. In this connection, in this paper, we propose the development of a wind turbine with an anti-icing system. This uses natural ventilation of the flow elements of the wind turbine with warm air, which does not allow the sticking of wet snowflakes on the surface of the apparatus and the formation of icing. [1] The present work is devoted to the study of the effect of geometric parameters of a turbine on its performance and some technological solution.
It is known that when designing a wind turbine, the designer needs to know the effect of the main parameters such as blade lengthening, the number of blades, blade thickness and filling factor on rotor productivity.

Currently, the main source of information for designing wind turbines with the Darrieus rotor is an experiment. The most complete and comprehensive results of experimental studies were published in [2-4].

In order to develop a semi-industrial version of the wind turbine, studies were conducted to determine the geometric parameters of the turbine. Thus, the calculations of the influence of design parameters on the energy characteristics of the turbine being 
developed with an anti-icing system have been performed.

\section{Determination of geometric parameters of the rotor influencing its energy characteristics}

1) Effect of lengthening the blade. The lengthening of the blade is one of the main parameters of the design of the Darrieus rotor, which determines its aerodynamic characteristics. The levels of aerodynamic loads, including the torque are depending from the magnitude of elongation. For a single blade, the nature of this dependence is almost the same as for the wing. For elongations $\lambda<1$, the magnitude of aerodynamic loads varies linearly from $\lambda$. With increasing elongation, these loads approach their asymptotic values for $\lambda>5$.

It follows from Fig. 1 that it is necessary to use blades with an elongation greater than 6 to provide an acceptable coefficient of wind energy utilization.

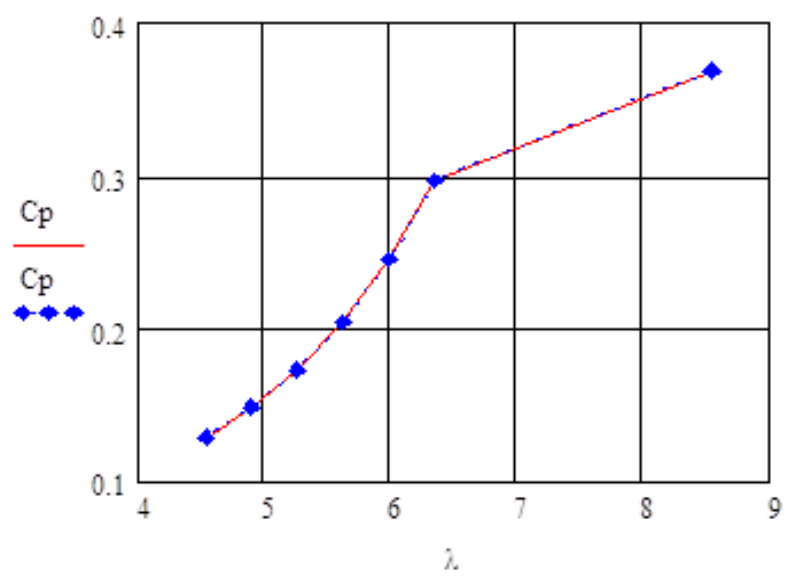

Figure 1 - Dependence of $\mathrm{C}_{\mathrm{p}}$ on the elongation of blades $n=2, b / D=0.167, R=1.65 \mathrm{~m}, \mathrm{l}=$ variable

2) The influence of the number of blades. Another important parameter of the design is the number of blades of the Darrieus rotor. To assess the influence of the number of blades on the energy characteristics of the rotor, special studies are carried out on rotor models with different number of blades.

The study shows that the single-blade rotor has the highest energy characteristics. But in this case, the torque is experiencing large pulsations in time, which gives rise to a bunch of dynamic problems. To smoother torque of the rotor we may increase the number of blades, but energy efficiency will decrease. This is especially pronounced when the number of blades is increased, their chord is reduced to maintain the constancy of the filling factor $\sigma$. It is more effective with increasing the number of blades to maintain the length of the chord.

Fig. 2 shows the results of calculations for the study of the influence of the number of blades at a constant filling factor. It can be seen that as the number of blades increases, the wind energy utilization factor decreases.

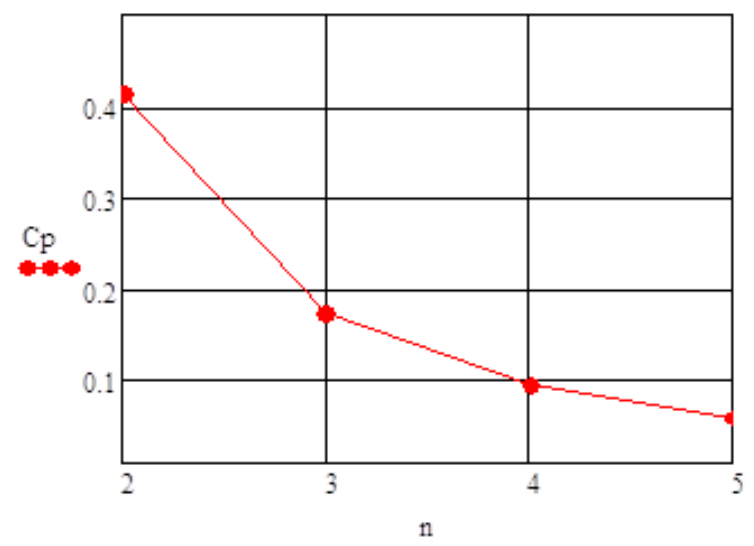

Figure 2 - Dependence of $\mathrm{C}_{\mathrm{p}}$ on the number of blades at a constant filling factor $\sigma=$ const, $\mathrm{l}=3.3 \mathrm{~m}$

Fig. 3 shows that with the blade width unchanged, the efficiency of $\mathrm{C}_{\mathrm{p}}$ falls less significantly than with constant filling with increasing number of blades.

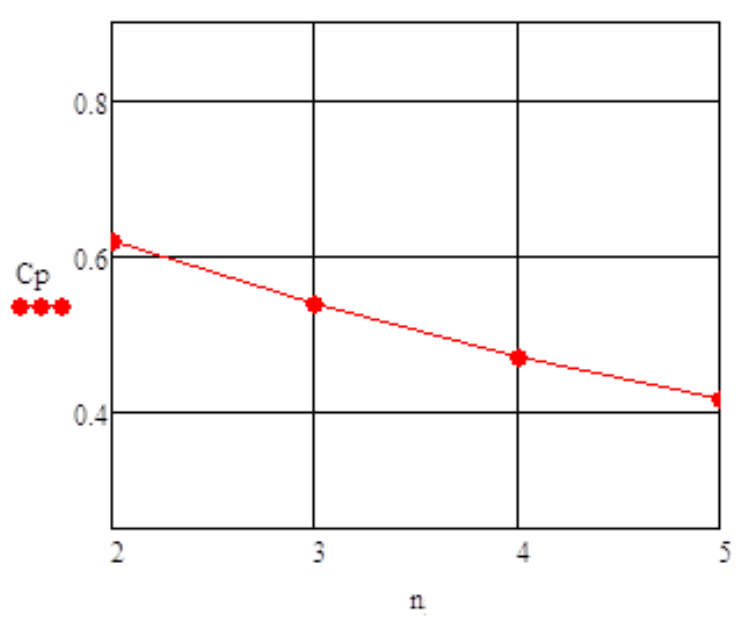

Figure 3 - Dependence of $\mathrm{Cp}$ on the number of blades with a constant width $b=$ const $, D=3.3 \mathrm{~m}, l=3.3 \mathrm{~m}$ 
3) Effect of blade thickness. The effect of the relative thickness of the blade profile on the value of the maximum value of the coefficient $\mathrm{C}_{\mathrm{p}}$ for different Reynolds numbers Re is shown in [5].

The greatest effect is achieved for blades with a relative thickness of $0.15<\mathrm{c}<0.20$. The main feature of this influence is associated with a sharp drop in $\mathrm{C}_{\mathrm{p}}$ for thin blades. It should be noted that the same character of the dependence on the relative thickness of the profile is observed for the traction force created by the flapping wing [2].

4) Influence factor effect. The filling factor is associated with two parameters of the rotor design: the number of blades $n_{b}$ and the ratio of the chord of the blade to the diameter of the rotor $\mathrm{b} / \mathrm{D}$. It should be noted that with an increase in the filling factor $\sigma$, the value of the rapidity of $z$ decreases, at which $C_{p}$ reaches its maximum.

In order to have $1 \mathrm{~kW}$ Darrieus rotor with direct blades with thermal protection, with an average wind speed $U$ of $7 \mathrm{~m} / \mathrm{s}$, we find the streamlined surface of the rotor according to the formula:

$$
\mathrm{S}=\frac{2 \mathrm{~N}_{\mathrm{b}}}{\mathrm{C}_{\mathrm{p}} \rho \mathrm{U}^{3}}
$$

where $\mathrm{N}_{\mathrm{b}}$ - power, $\mathrm{W} ; \mathrm{C}_{\mathrm{p}}-$ wind utilization coefficient is equal to $0.4 ; \rho-1.29 \mathrm{~kg} / \mathrm{m}^{3}$ - air density.

The streamlined area of the rotor with a power of $1 \mathrm{~kW}$ should be $11.3 \mathrm{~m} 2$. If we assume that the rotor diameter $\mathrm{D}$ and the blade height 1 are equal, then $\mathrm{D}=$ $1 \approx 3.36 \mathrm{~m}$. With an experimentally valid lengthening of the blade $\lambda=1 / \mathrm{b}=6-8$, the length of the chord of the blade can be $b=3.36 /(6-8)=0.56-0.42 \mathrm{~m}$, and the chord, on average, will be $b=0.55 \mathrm{~m}$.

Since the maximum value of the coefficient $C_{p}$ for different Re values is achieved for blades with a relative thickness of $0.15<\mathrm{c}<0.20$, we take the relative thickness equal to 0.18 . Proceeding from this, the maximum thickness of the blade, as a fraction of the length of the chord, should be $0.09 \mathrm{~m}$. And the fill factor in turn will be equal to:

$$
\sigma=\frac{\mathrm{n}_{\mathrm{b}} \mathrm{b}}{\mathrm{D}}=0.33
$$

It is important to note that the filling factor $\sigma$ satisfies the conditions under which $\mathrm{C}_{\mathrm{p}}$ reaches its maximum.

Using application packages for mathematical calculations, we can obtain the area and perimeter of the cross section. For our rotor, the perimeter of the wing was $\Phi=1.04 \mathrm{~m}$ and the ratio to the chord $\mathrm{b}$ is approximately 2.1. The cross-sectional area $\mathrm{f}_{1}=0.0154 \mathrm{~m}^{2}$.

Thus, geometric parameters influencing the energy characteristics of a turbine with thermal protection were determined, and internal hydraulics and warm air motions along internal channels are described in detail in $[1,6,7]$.

\section{The limitation of carousel type wind turbine and its technical solution}

The main disadvantage in the vertical position: the vertical axis of rotation and its vertical mounting in the bearing supports. The manufacture of supports is also a complex technological task; it is required to ensure the alignment of the supports and their rigidity. Also, a disadvantage of the design is the large mass of the shaft, which presses on the lower rotational support, creates a large friction torque, which reduces the efficiency of the installation [8].

It is clear that the task of making such a shaft and its installation in a hull is a complex task. As a solution to this problem, a modular system is used. It is made from several parts-modules, and then assembled in place in one unit.

In this paper, we propose another method for solving this complex technological problem. Renounce a long rotating shaft and replace it with a short axis, on which two bearings will rotate with a wind wheel attached to them. Application of the proposed design of the wind farm will simplify the manufacturing technology. In the old design, it was necessary to have a long rotating vertical shaft, which must be fixed in two places below and above. For a $1 \mathrm{~kW}$ wind turbine, a shaft of about $8 \mathrm{~m}$ in length is required. The length of the shaft is almost equal to the length of the rotor. From above, the shaft could not be shorter than the rotor, since it is necessary to secure the upper shaft support, usually it was taut cables. It is clear that the production of such a shaft, with the achievement of coaxially and rigidity, the most complicated technological task, a special lathe capable of processing such long blanks with the required accuracy is necessary. Such a shaft is difficult to mount and provide support at the top and also affects the cost of the wind farm. The advantage of the proposed scheme is that a fixed rigid support is placed on the base (see Fig.4.), in which it is necessary to ensure alignment in the installation sites. The distance between the bearings can be 2-3 times the height of the support. In the new design, the shaft rotates inside a rigid rela- 
tively short body $1.0 \mathrm{~m}$ long. Bearing misalignment can also have a sufficiently large value of $1-2 \mathrm{~mm}$. This error will be compensated by the elasticity and flexibility of the blade design itself.

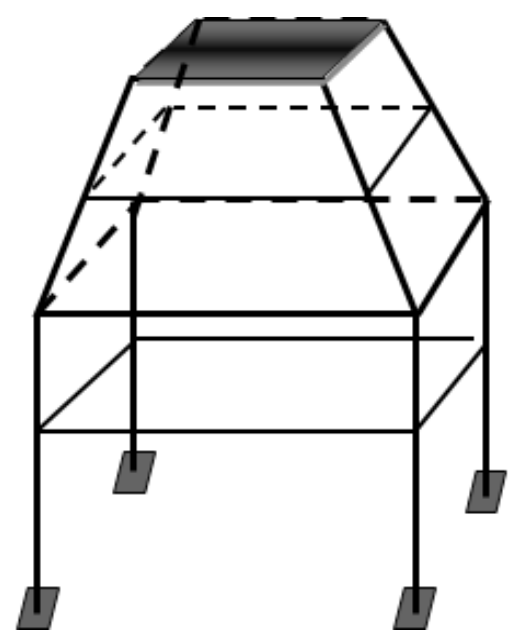

Figure 4 - Fixed rigid support

The shaft does not require high structural requirements, since the shaft does not have original surfaces.

All these factors greatly simplify the technology of manufacturing a wind power plant, by about 25 $30 \%$. It should be noted that it is the problem of a long vertical shaft that is the main one, which constrains the wide application of rotor wind turbines in practice. Also, the mass of the shortened structure with the hollow internal shaft is much smaller than the mass of the long shaft; therefore, the force of their weight will create a much smaller friction torque in the lower rotational support, which undoubtedly will increase the efficiency of the installation. This solution can be used in any scheme of a wind farm with a vertical axis of rotation of the rotor, for example, the scheme of Savonius, Darrieus, Evans, Musgrove, carousel, etc. [8,9].

Wind installation with a shortened construction from the point of evaluation for manufacturability has a number of advantages, since the design is oriented to manufacturing in small shops, which gives a reduction in the technological cost. This design also has the advantage of being transported to remote areas for the use of farms and in small businesses.

The assembly structure consists of 12 parts (see Fig.5.). A rigid shortened body is assembled on the mounting housing 7. The rotor assembly is assem- bled on the mounting housing assembly on the keyway and fixed with a special nut to the rotating shaft 1. All assemblies can be mounted on supports of various designs and heights.

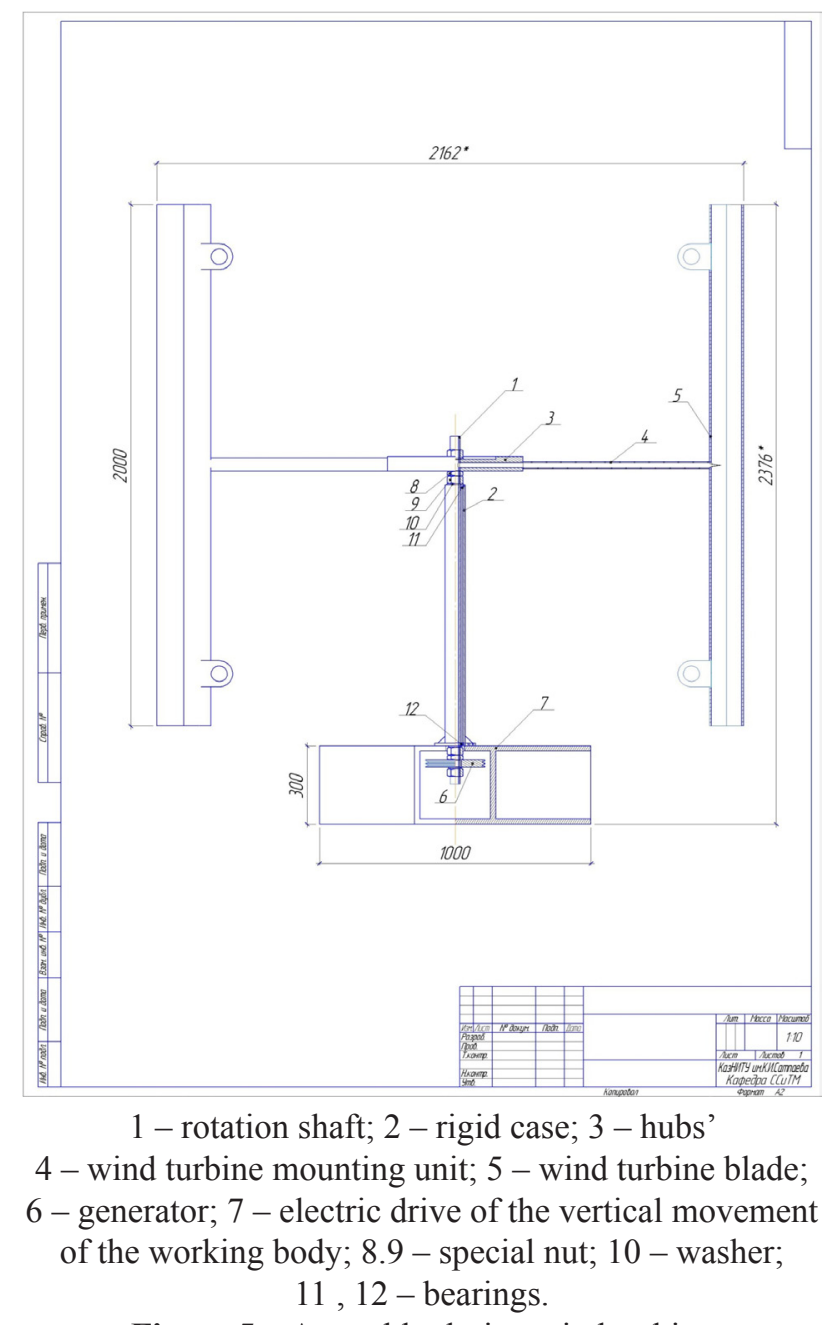

Figure 5 - Assembly design wind turbine

Blades 5 windmill is made of aluminium and welded to the guiding body 4 by argon welding.

The guide body assembly is welded to the hub 3 according to the working drawing of the rotor assembly. The shortened rigid body 2 is made of a standard thick-walled tube of steel CT 3. Two standard bearings 11 and 12 are used in this design. For its intended purpose, the thrust bearing 11 is thrust, since it is affected by the weight of the rotor assembly. The lower radial single row bearing 12 operates on the rotational movement of the torque transmission from the pulley 6 to the generators generated electrical energy. 
A $2 \mathrm{~m}$ long chord and a $0.5 \mathrm{~m}$ chord will be made of aluminium AD0 according to GOST 4784-97 or aluminium grade 1050 according to EN 573-3 with a thickness of $2 \mathrm{~mm}$. Using tabular data with $\mathrm{x}$ values, the distance from the profile's bottom (in relative units, from 0 to 1 , or percentages), $y_{t}$ is the coordinate of the top point and $y_{b}$ is the coordinate of the bottom point of the profile (also in relative units or percentages). For the symmetrical wing profile NASA-0021, the volume of the blade of the installation was determined. The density of aluminium is $\rho=2712 \mathrm{~kg} /$ $\mathrm{m}^{3}$. Thus, the mass of one blade of the symmetrical wing profile NASA- 0021 is $m=11.366 \mathrm{~kg}$. Since we have 2 blades, the total mass of the blades will be $\mathrm{m}$ $=22.732 \mathrm{~kg}$.

Swing length of $1 \mathrm{~m}$ and chord $0.5 \mathrm{~m}$, as well as the blade, will be made of aluminum AD0 according to GOST 4784-97 or aluminum grade 1050 according to EN 573-3 with a thickness of $2 \mathrm{~mm}$. Using the previous method, the mass of the fly was also determined, which is equal to $\mathrm{m}=11.366 \mathrm{~kg}$.

The shaft of rotation of the installation with a length of $1.334 \mathrm{~m}$ and an inner diameter $\mathrm{dB}=24 \mathrm{~mm}$

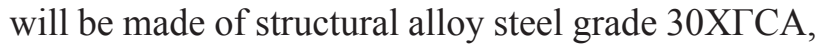
density of which is equal to $\rho=7850 \mathrm{~kg} / \mathrm{m}^{3}$. With the help of the drawing, the volume of the rotation shaft was calculated. Multiplying the volume of the shaft by the density of the material, we determined the mass of the shaft $m=1.688 \mathrm{~kg}$.

Using the drawings, the mass of the outer casing was determined, which will also be made of structural alloy steel grade $30 \mathrm{ХГСА,} \mathrm{density} \mathrm{of} \mathrm{which} \mathrm{is}$ equal to $\rho=7850 \mathrm{~kg} / \mathrm{m}^{3}$. The mass of the outer tube is $\mathrm{m}=17.34 \mathrm{~kg}$.

As a result, having combined the masses of all the parts of the installation, the mass of the actual installation was determined to be $\mathrm{m}=53.126 \mathrm{~kg}$ [10].

\section{Conclusions}

The dependence of the maximum coefficient of wind energy use of vertical axle wind wheels on the number of blades at a constant filling factor $\sigma$, on the number of blades at their constant width, on the lengthening of the blade $\lambda$ is studied. The geometric characteristics of the blade and fly are obtained, which are the main parts of the rotor, which affect its energy efficiency.

Technological design of the components of the wind power plant has a direct relationship with labor productivity, time spent on technological preparation of production, manufacturing, maintenance and repair of the product. Therefore, the design of the technological process for the manufacture of parts must be preceded by an analysis of the technological nature of its design and, if necessary, processing for manufacturability. Technological design of the details of the wind power plant is estimated at two levels qualitative and quantitative. A qualitative assessment and quantitative demonstration of the conformity of the design of parts during the analysing the designs of a wind power plant should met the following requirements:

- the design of the wind turbine shall be standard or consist of standard and unified structural elements;

- standard and unified blanks are used for the manufacturing of details of the wind turbines;

- dimensional accuracy and surface roughness of wind turbine components are optimal, reasonably structurally and economically;

- in determining the rigidity, shape and size, as well as the mechanical and physicochemical properties of its material, the components of the windmill were taken into account the capabilities of the manufacturing technology, storage and transportation conditions;

- accuracy and roughness of the surfaces of the components of the windmill ensure the required accuracy of installation, processing and control;

- the procurement of the components of the wind turbine must be obtained in a rational way (taking into account the volume of output and the type of production);

- in all designs of wind turbine parts, access to the surfaces to be treated and the possibility of simultaneous processing of several blanks;

Based on the analysis of the initial information of the wind turbine (the assembly drawing of the unit, the drawing of the part, the program and the annual volume of output, the type of production, the service purpose of the unit and the part), one can draw a conclusion on the expediency of a fundamental change in the method of obtaining the initial billet.

The correspondence of the surface, which will be used as technological bases, is revealed, and compliance with their requirements to the technological bases of the billet is checked. The total mass of a real installation is determined using the drawings. Also, for each part, a selection of materials was made from which the plant will be manufactured. 


\section{Nomenclature}

$\lambda$ - Elongation;

$C_{p}-$ wind energy utilization coefficient;

$n$ - Number of blades;

$b$ - Chord of the blade, m;

$D$ - Diameter, m;

$R$ - Radius, $\mathrm{m}$;

$l$ - Blade's height, $\mathrm{m}$;

$\sigma-$ Filling factor;

c - Relative thickness;

Re - Reynolds number;

$\mathrm{U}-$ average wind speed, $\mathrm{m} / \mathrm{s}$

$\Phi$ - perimeter of the wing, $\mathrm{m}$;

$\mathrm{f}_{1}-$ cross sectional area, $\mathrm{m}^{2}$.

\section{References}

1. R.K. Manatbayev, A. Georgiev, R. Popov, D. Dzhonova-Atanasova, A.A. Kuikabayeva, E.M. Zulbukharova. The effect of design parameters on energy characteristics of Darrieus rotor. International journal of mathematics and physics, 74, 94-98 (2016).

2. D.N.Gorelov. The analogy between the flapping wing and the wind wheel with the vertical axis of rotation. Applied mechanics and technical physics, 50, 152-155 (2009).

3. D.N.Gorelov, I.N.Kuzmenko, Experimental evaluation of the limiting power of a wind wheel with a vertical axis of rotation, Thermal physics and aero mechanics, 8, 329-334 (2001)

4. A.K.Ershina, R.K.Manatbaev, Organization of natural ventilation inside the working Darrieus turbine, Small energetics, 1-2, 63-66 (2013)

5. A.K.Ershina, R.K.Manatbaev, Determination of the hydraulic resistance of the symmetrical wing profile NASA-0021, KazNU bulletin: mathematics, mechanics and informatics section, 51, 56-58 (2006)

6. K.J.Thuryan, D.Strickland, D.E.Berg, Power of wind turbines with a vertical axis of rotation, Aero cosmic technics, 1988

7. D.N.Gorelov, Aerodynamics of vertical axed wind turbines, KAN Polygraph center, 2012

8. D.DeRenzo, I.I.Shefter, Wind energy, Energoatomizdat, 1982

9. Manatbayev R.K., Yershina Sh. A., Yershina A.K.Method for Thermally Protecting Operating Revolving Type Wind-Power Installation, Involves Causing Internal Natural Ventilation in Wind Unit by Centrifugal Force to Heat All Elements of Wind-Power Installation by Warm Air. Patent Number(s):RU2008137251-A; RU2447318C2International Patent Classification:F03D-003/00 Derwent Class Code(s): Q54 (Starting, ignition); X15 (Non-Fossil Fuel Power Generating Systems) Derwent Manual Code(s): X15-B01A6

10. Askarov E.S. Wind power plant with vertical axis of rotation of the wind wheel, KZ Patent№2219 